\title{
COMBINED AORTIC AND MITRAL STENOSIS
}

\author{
BY \\ J. M. REID, J. G. STEVENSON, R. S. BARCLAY, AND T. M. WELSH \\ From the Cardio-Thoracic Surgical Unit, Mearnskirk Hospital, Renfrewshire
}

Received February 18, 1962

While mitral stenosis is still frequently encountered despite the large decline in the incidence of acute rheumatism, combined mitral stenosis and aortic stenosis is less common. The recognition of the existence of aortic stenosis in association with mitral stenosis is important, as both can be dealt with successfully at one operation. If the aortic lesion goes undetected and mitral valvotomy alone is performed, the results may sometimes prove disastrous (Ross, 1959).

Honey (1961) recently reviewed the clinical and hæmodynamic features of 35 patients with this combination, 32 of whom were operated on. The present series comprises 15 patients seen at Mearnskirk Hospital between November 1957 and January 1962, all of whom underwent surgical treatment. The symptoms and clinical features of combined aortic and mitral stenosis are compared with those of isolated aortic stenosis. A further five had mitral stenosis with an aortic systolic murmur but the aortic gradient at operation was regarded as insignificant.

\section{Clinical Aspects of Our 15 Patients}

The sex incidence was 2:1 in favour of women. The ages of the patients ranged from 26 to 46 years, with a preponderance in the 40 to 46 group as shown below:

\begin{tabular}{c|c|c|c}
\hline \multicolumn{4}{c}{ Age group (years) } \\
\hline $26-29$ & $30-34$ & $35-39$ & $40-46$ \\
\hline 1 & 5 & 1 & 8 \\
\hline
\end{tabular}

All suffered from predominant stenosis of the mitral and aortic valves, and regurgitation where present was insignificant. In nine $(56 \%)$, there was a previous history of rheumatic fever. In the series reported by Honey (1961) two-thirds gave a history of rheumatic fever.

The presenting symptom in every case was exertional dyspnœa, varying in severity from Grade II to IV. Eleven fell into Grade II, two into Grade III, and the remaining two were in moderately severe congestive cardiac failure. Peripheral œdema was observed in three patients only but was never gross. Effort syncope, a common accompaniment of severe aortic stenosis, was encountered in only 1 of our 15 patients. In isolated aortic stenosis, too, angina of effort occurs relatively frequently, and Anderson (1961) found it in 20 out of 49 patients. It was encountered in only 3 of our patients due either to inadequacy of the coronary blood flow or to the low cardiac output associated with the accompanying mitral stenosis. In no case did it produce any evidence of ischæmia on the electrocardiogram at rest. 
The auscultatory findings were those of mitral stenosis, with an accompanying systolic murmur $\stackrel{c}{\mathrm{C}}$ over the aortic area, conducted characteristically into the root of the neck. Atrial fibrillation was present in 4 patients. Anderson (1961) emphasized that this arrhythmia was of exceptional $\stackrel{\text { ? }}{\circ}$ occurrence in isolated aortic stenosis, being met with only in its terminal phase as a presage of $\frac{}{\circ}$ irreversible cardiac failure.

Left ventricular hypertrophy of varying degree was noted on the electrocardiogram in 9 patients, and in 3 it was moderately severe. Left bundle-branch block was not observed in any patient.

On fluoroscopy enlargement of the left ventricle was seen in 9 patients, although it was never severe. Calcification of either the mitral or the aortic valve was not discernible in any case on screening, although its presence was confirmed at operation in no less than eight. The clinical and hæmodynamic aspects are shown in Table I.

TABLE I

Clinical Aspects of 15 Patients with Combined Aortic and Mitral Stenosis

\begin{tabular}{|c|c|c|c|c|c|c|c|c|c|c|}
\hline \multirow{2}{*}{ No. } & \multirow{2}{*}{$\begin{array}{c}\text { Dyspnœea } \\
\text { (grade) }\end{array}$} & \multirow{2}{*}{$\begin{array}{c}\text { Edema } \\
\text { (O), } \\
\text { angina } \\
\text { (A), or } \\
\text { syncope } \\
\text { (S) }\end{array}$} & \multirow{2}{*}{$\begin{array}{l}\text { Congest. } \\
\text { cardiac } \\
\text { failure }\end{array}$} & \multicolumn{2}{|c|}{ L.V. enlargement } & \multirow{2}{*}{$\begin{array}{l}\text { P.A. } \\
\text { pressure }\end{array}$} & \multicolumn{2}{|c|}{$\begin{array}{l}\text { Aortic systolic } \\
\text { gradient }\end{array}$} & \multicolumn{2}{|c|}{ L.V. pressure } \\
\hline & & & & $\begin{array}{l}\text { on } \\
\text { EC. }\end{array}$ & $\begin{array}{c}\text { on } \\
\mathrm{X} \text {-ray }\end{array}$ & & Before & After & Before & After \\
\hline 1 & II & - & - & +- & + & $45 / 25$ & 45 & 20 & $125 / 60$ & $95 / 15$ \\
\hline 2 & I & - & - & +- & + & - & & - & - & נהונת \\
\hline 3 & III-IV & OA & +- & +- & + & + & - & - & - & \\
\hline 4 & II & - & - & +- & - & $15 / 0$ & 45 & 12 & $150 / 0$ & $102 / 0$ \\
\hline 5 & II & - & - & - & - & $60 / 40$ & 10 & 0 & $100 / 20$ & $80 / 20$ \\
\hline 6 & III-IV & O & +- & - & - & $160 / 40$ & 25 & - & - & - \\
\hline 7 & II & - & - & - & + & $40 / 20$ & 25 & 0 & $140 / 0$ & $120 / 0$ \\
\hline 8 & II & A & - & + & + & + & 35 & 0 & $110 / 20$ & $90 / 15$ \\
\hline 9 & II & - & - & - & - & $50 / 25$ & 30 & 20 & $125 / 15$ & $125 / 15$ \\
\hline 10 & II & - & - & - & - & $45 / 30$ & 65 & 5 & $160 / 25$ & $125 / 25$ \\
\hline 11 & III & O & - & +- & +- & $35 / 20$ & 48 & 20 & $110 / 0$ & $150 / 0$ \\
\hline 12 & II & AS & - & + & + & $45 / 25$ & 100 & 35 & $175 / 0$ & $160 / 0$ \\
\hline 13 & II & - & - & - & + & $45 / 25$ & 65 & 32 & $160 / 10$ & $132 / 10$ \\
\hline 14 & II-III & - & - & + & + & $35 / 20$ & 70 & 40 & $140 / 0$ & $120 / 0$ \\
\hline 15 & II & - & - & + & - & + & 105 & 45 & $180 / 0$ & $110 / 0$ \\
\hline
\end{tabular}

Cardiac Catheterization. In only one patient was catheterization of the left heart attempted: the technique employed was that of percutaneous puncture of the left ventricle, combined with retrograde catheterization of the aorta by means of the radial artery, to assess the aortic systolic gradient. We feel that while left heart catheterization is mandatory in isolated aortic stenosis to $\frac{\text { ㅇ }}{}$ determine whether the gradient is of sufficient severity to warrant surgical intervention, it is not so $\frac{D}{0}$ essential in the presence of an accompanying obstruction of the mitral valve requiring obvious surgical relief. In such cases, pressures across the aortic valve can be obtained very accurately at $\mathbb{N}$ the time of operation.

Right heart catheterization was performed in 7 patients to obtain pressures in the pulmonary $\mathcal{N}_{\mathrm{N}}$ trunk and in the lung periphery ("wedge pressure"). In addition, it facilitates calculation of the cardiac output and the pulmonary vascular resistance.

The pressure in the pulmonary trunk measured at operation was found to be raised in 14 patients. This was gross in one patient (Case 6), the recorded pressure being $160 / 40 \mathrm{~mm}$. Hg. The pulmonary vascular resistance was also very raised in this patient, exceeding 10 units. In no other instance was a raised pulmonary vascular resistance encountered.

The systolic gradient across the aortic valve before valvotomy ranged from $10-105 \mathrm{~mm}$. $\mathrm{Hg}$, with a mean of 48. Following relief of the obstruction, there was a satisfactory fall in the gradient to a mean of 16. The highest left ventricular pressure recorded was $180 / 0 \mathrm{~mm}$. $\mathrm{Hg}$ (Case 15). The aortic systolic gradient here was 105 before valvotomy but dropped to 45 following this procedure. 
Correlation between Left Ventricular Pressure and Signs of Left Ventricular Hypertrophy. There was no close relation between the height of the pressure in the left ventricle and the enlargement of the left ventricle on the cardiographic or X-ray evidence. Admittedly, in the two patients with gradients of 100 and above, there was cardiographic evidence of left ventricular hypertrophy, but in two others with gradients above 60 , there was no radiological evidence of enlargement of that chamber. It is noteworthy that the left ventricular pressure in patients with combined mitral and aortic stenosis never reaches the height found in those with isolated aortic stenosis. Honey (1961) found a left ventricular pressure exceeding 170/0 in only 2 of his 35 patients, In contrast, Baker and Somerville (1959) found the left ventricular pressure to be above $170 / 0$ in all 50 patients operated on for isolated aortic stenosis, the most severe being in the region of $260 / 0 \mathrm{~mm}$.

Valve calcification was present in the aortic valve in 8, and in the mitral valve in 6 patients. In no way did it contribute to the severity of the stenosis in either valve, nor did it necessarily prejudice a successful double valvotomy. However, in the sole instance of post-operative embolism (Case 14), both valves were found to be heavily calcified at operation: here the embolus lodged in the left common iliac artery and its presence was noted almost immediately on his return from theatre. Fortunately, effective collaterals were present and with a conservative regimen the ischæmic changes receded within the ensuing six days, and ultimately there was little or no impairment of the circulation to the limb.

Additional Pre-operative Data. Tests of lung function were carried out in one patient (Case 15). These disclosed normal ventilatory function and normal diffusing capacity. The respective results were as follows (the predicted values being in parentheses): vital capacity $2500 \mathrm{ml}$. (2885 ml.); M.V.V. 80 1. $\left(85\right.$ 1.); and P.E.F. 350 1. (350 1.). The carbon monoxide diffusing capacity $\left(\mathrm{D}_{\mathrm{co}}\right)$ was recorded as $46 \mathrm{ml} . / \mathrm{min} . / \mathrm{mm}$. at rest, with a rise to 59 on exercise.

Severity of Mitral and Aortic Stenosis as Assessed at Operation. The orifice of the mitral valve was estimated at operation as below $2.5 \mathrm{~cm}$. in 11 patients. These can be classified as representing fairly severe stenosis and all had pulmonary hypertension. A satisfactory $3.5 \mathrm{~cm}$. or $4.5 \mathrm{~cm}$. split was achieved by means of the mechanical dilator. In only one instance was a digital valvotomy performed due to circumstances pertaining at operation.

The obstruction of the aortic valve was regarded as severe in all 15 patients, although in only five did the aortic gradient exceed $60 \mathrm{~mm}$. Hg.

Apart from the 15 patients under discussion, a further 5 were encountered with mitral stenosis and an accompanying aortic systolic murmur. None had either cardiographic or radiological evidence of left ventricular hypertrophy, and at operation the aortic systolic gradient was below $10 \mathrm{~mm}$. in all. Pulmonary hypertension was uniformly present and a successful mitral valvotomy was accomplished. No attempt was made to split the aortic valve.

\section{IMMEDIATE MORTALITY}

All the four deaths that occurred were in the early part of our series when the operative technique was still being perfected and proper selection of patients for operation was not appreciated. The following is a brief description of the operation findings and the cause of death in each.

Case 1. A man, aged 22 years, had severe stenosis of both valves confirmed at operation. Severe calcification was present in both, and this was so extreme in the mitral valve that even with the dilator and using extreme force, an effective split could not be achieved. Following operation his condition was grave. He remained extremely cyanosed, and progressed inexorably to cardiac failure, dying in coma 23 days after operation. At autopsy, both valves were found to be heavily calcified, and both were still markedly stenosed.

Case 2. A man, aged 41 years, developed ventricular fibrillation shortly after the chest had been opened. The pericardium was incised expeditiously and both coronary arteries were observed to be very atherosclerotic. In brief stages, between spells of cardiac massage, first a digital mitral valvotomy, and then an instrumental aortic valvotomy, were performed. Thereafter, electrical defibrillation, followed by a further period of massage, restored normal contractions of the heart. On return from theatre, his condition appeared reasonably satisfactory. However, later that same evening, he collapsed suddenly and death was almost 
instantaneous. At necropsy, the gross sclerosis of both coronary vessels noted at operation was confirmed $\stackrel{.}{.}$ and the myocardium itself showed areas of fibrosis. Although both mitral and aortic valves showed extensive calcification, an adequate split of both appeared to have been achieved.

Case 5. A combined mitral and aortic valvotomy was carried out successfully in this woman, aged 34 years. Both valves were split to $4.5 \mathrm{~cm}$., but great force was required to split the aortic one. Cardiac arrest ensued ten minutes after return from theatre, and massage and other resuscitative measures proved unavailing. Necropsy disclosed rupture of the aortic ring, with an extensive longitudinal tear into the body of the left ventricle. It was concluded that too much force had been exerted in trying to achieve an effective aortic of split, and that the instrumental setting of $4.5 \mathrm{~cm}$. was too wide. Since then, the instrument has never been $\vec{\circ}$ used above $3 \mathrm{~cm}$. for the aortic valve.

Case 6. Gross irreversible pulmonary hypertension (160/40) was largely responsible for a fatal outcome in this patient, aged 50 years. After thoracotomy, cardiac action was noted to be extremely poor, but it improved after relief of the mitral obstruction. However, when attention was directed to the aortic valve, cardiac contractions once more became feeble, and the output was very low. Despite a lengthy period of massage, the heart failed to improve and death ensued. Subsequent examination revealed that while a satisfactory mitral split had been accomplished, there was still severe stenosis of the aortic valve. The lungs were very rigid and non-compliant, in keeping with the severe pulmonary hypertension recorded at operation. Death was attributable to the latter, with inadequate relief of the aortic obstruction a contributory factor.

\section{RESULTS}

Some of the results are shown in Table II. Of the 11 survivors the end result has been excellent in 5, as established by standard criteria. They have an exercise tolerance that is virtually normal, they do not require any medication in the form of digoxin or diuretics, and they are able to pursue their normal occupations and activities without any reservation. Two have been classed as good in that while there is improvement in their clinical condition, they are still on either maintenance digoxin or periodic diuretic therapy. A further two are improved but are unable to undertake any strenuous exertion, and permanent atrial fibrillation is present. One patient (Case 3) has shown little or no improvement since operation: this is hardly surprising as before operation he had

TABLE II

Surgical Data on 15 Patients with Combined Aortic and Mitral Stenosis

\begin{tabular}{|c|c|c|c|c|c|c|c|}
\hline \multirow{2}{*}{ No. } & \multicolumn{2}{|c|}{ Size of mitral valve } & \multicolumn{2}{|c|}{$\begin{array}{l}\text { Size of aortic valve } \\
(\mathrm{cm} .)\end{array}$} & \multicolumn{2}{|c|}{ Calcification } & \multirow{2}{*}{ Result } \\
\hline & Before & After & Before & After & Aortic & Mitral & \\
\hline $\begin{array}{l}1 \\
2\end{array}$ & $\begin{array}{l}1.5 \\
2.5\end{array}$ & $\begin{array}{c}2 \cdot 5 \\
\text { Digital }\end{array}$ & $\overline{-}$ & $\begin{array}{l}3.0 \\
2.5\end{array}$ & $\stackrel{+}{+}$ & + & $\begin{array}{l}\text { Died } 23 \text { days after operation } \\
\text { Died; ventricular fibrillation } \\
\text { (coronary artery sclerosis) }\end{array}$ \\
\hline $\begin{array}{l}3 \\
4\end{array}$ & $\begin{array}{l}1.0 \\
1.5\end{array}$ & $\begin{array}{l}4 \cdot 5 \\
3 \cdot 5\end{array}$ & $\begin{array}{l}2.0 \\
2.0\end{array}$ & $\begin{array}{l}3 \cdot 0 \\
3 \cdot 5\end{array}$ & + & $\stackrel{+}{+}$ & $\begin{array}{l}\text { Poor; mitral and aortic incomp. } \\
\text { Died } 6 / 12 \text { later from L.V. failure; } \\
\text { aortic stenosis at necropsy }\end{array}$ \\
\hline 5 & $2 \cdot 5$ & $4 \cdot 5$ & - & $4 \cdot 5$ & +- & + & $\begin{array}{l}\text { Died } 1 \text { hour after operation. } \\
\text { P.M.-ruptured aortic cusp } \\
\text { +A.I. }\end{array}$ \\
\hline 6 & $1 \cdot 5$ & $4 \cdot 5$ & $2 \cdot 0$ & $4 \cdot 0$ & - & - & $\begin{array}{l}\text { Died } 1 \text { hour after operation. } \\
\text { P.M. still A.S. but severe pulm. } \\
\text { hypertension }(160 / 40)\end{array}$ \\
\hline $\begin{array}{l}7 \\
8\end{array}$ & $\begin{array}{l}1.5 \\
1.5\end{array}$ & $\begin{array}{l}4.5 \\
4.5\end{array}$ & 二 & $\begin{array}{l}4 \cdot 5 \\
4 \cdot 0\end{array}$ & \pm & $\overline{-}$ & Excellent \\
\hline$\stackrel{8}{9}$ & $1 \cdot 5$ & $\begin{array}{l}4.3 \\
4 \cdot 5\end{array}$ & 二 & $\begin{array}{l}4.0 \\
3.0\end{array}$ & $\overline{-}$ & $\overline{-}$ & Good \\
\hline 10 & $2 \cdot 0$ & $4 \cdot 5$ & - & 3.0 & - & - & Excellent \\
\hline 11 & $2 \cdot 5$ & 4.0 & - & $3 \cdot 0$ & - & - & Good \\
\hline 12 & $\overline{1.5}$ & $\begin{array}{l}3 \cdot 5 \\
3 \cdot 5\end{array}$ & 二 & $\begin{array}{l}3 \cdot 0 \\
3 \cdot 0\end{array}$ & $\bar{z}$ & $z$ & $\begin{array}{l}\text { Excellent } \\
\text { Excellent }\end{array}$ \\
\hline 14 & 1.0 & $3 \cdot 5$ & 二 & 3.0 & + & + & Good \\
\hline 15 & $2 \cdot 5$ & $3 \cdot 5$ & - & 3.0 & + & - & Excellent \\
\hline
\end{tabular}


severe exertional dyspnœa (Grade III, verging on IV) and had suffered from several attacks of congestive cardiac failure. Both the aortic and mitral valves were heavily calcified and grossly deformed at operation, and the prospect of achieving a successful result seemed remote. Double valvotomy, nevertheless, was performed, and although the obstructive element was removed, it was at the expense of producing moderately severe regurgitation in both valves.

The final patient (Case 4) merits particular consideration. Following operation he pursued an extremely stormy course, during which period his temperature remained raised for several weeks and he developed an obvious anæmia. Blood culture yielded hæmolytic streptococci, and he was treated with large doses of penicillin. Thereafter, he developed a recrudescence of his rheumatic state, with a return of pyrexia, joint pains, and a strongly positive C-reactive protein. Salicylate therapy at this stage produced a good therapeutic response with subsidence of the fever and joint pains. After a protracted convalescence, he was discharged home and eventually resumed work. However, six months after operation, he was admitted to another hospital as an emergency with acute left ventricular failure. Shortly after, he collapsed quite suddenly and died almost immediately. Necropsy showed the cause of death to be severe aortic stenosis. The mitral valve had an orifice approaching normal but the aortic valve was almost pin-hole. The assumption is that the flare-up of his rheumatism post-operatively had caused further cardiac damage, singling out the aortic valve.

\section{Discussion}

The ideal approach to aortic valvular disease, particularly in the younger age groups, is admittedly by open heart technique employing either hypothermia (Baker and Somerville, 1959), or cardio-pulmonary bypass (Ellis and Anderson, 1961). If the valve is grossly deformed or incompetent, an artificial one may be inserted in these circumstances. However, in the older age groups and where there is an accompanying obstruction of the mitral valve, a less radical approach may produce satisfactory results, with a decreased operative mortality. Such a method employing the transventricular route permits an adequate splitting of both aortic and mitral valves.

In our series, although 15 had moderate to severe aortic stenosis requiring operative relief, in only 9 was there evidence of left ventricular hypertrophy on the cardiogram or on X-ray examination. However, of the 5 with an aortic systolic gradient of 65 or above, evidence of such was present before operation in three. Severe obstruction of the mitral valve (an orifice less than $2.5 \mathrm{~cm}$.) was present in three of these. It is significant that in the two with the highest gradient (100 and 105, Cases 12 and 15 respectively), the mitral stenosis was not severe. Conversely, the aortic gradient in all those with gross obstruction of the mitral valve was below 65 (Table II), yet all had critical aortic stenosis requiring surgical relief.

Calcification of the aortic valve was present in 8 patients, a much higher incidence than that reported by Honey (1961) who confirmed valvular calcification in only 8 out of 35 . The presence of calcification presents two additional operative hazards. First, it is more difficult to split such a valve, and there is the potential risk of producing regurgitation or tear of an aortic cusp (as in Cases 3 and 5). However, it does not necessarily prejudice a satisfactory result, as evidenced in Cases 7, 14, and 15. The second danger is that of calcium embolus.

The surgical technique has been basically the same in all cases, although certain modifications have been made. Pressures are recorded in left ventricle, aorta, left atrium, and pulmonary artery, shortly after incision of the pericardium. An estimate is made of the size of the mitral valve by finger palpation from the left atrial appendage. The presence or absence of calcification, type of valve, and the existence of appreciable regurgitation are all noted. Valvotomy through the left ventricle is then performed by the dilator, the instrument being set at a predetermined level depending on the size of the orifice and type of valve. Next, the dilator is passed through the outflow tract of the left ventricle and an assessment made of the width of the aortic valve. Finally, aortic valvotomy is carried out, and when cardiac action and circulation are restored to adequate levels as judged by visual inspection of the heart's contractions, blood pressure, and cardiac rate, pressures in all four chambers are recorded.

$2 \mathrm{~L}$ 
In the earlier part of the series the aortic valve was split to $4.5 \mathrm{~cm}$. This was subsequently reduced to a $3.0 \mathrm{~cm}$. split because of rupture of an aortic cusp with fatal result in Case 5, and the production of regurgitation in two others.

An operative mortality of 27 per cent (4 deaths in 15 cases) certainly leaves little ground for complacency. Such a figure must be regarded in its proper perspective, however, bearingin mind the gravity of unrelieved severe aortic stenosis, either alone or combined with mitral obstruction. All the deaths occurred early in the series. Coronary arterial disease contributed largely to one of the deaths, while very gross, irreversible, pulmonary hypertension was a major factor in a second. Faulty surgical technique undoubtedly produced a fatal outcome in the remaining two patients.

The importance of recognizing associated aortic valve disease in the presence of established mitral stenosis, has already been mentioned. Failure to do so can either prejudice the result of a successful mitral valvotomy or produce a fatal outcome (Ross, 1959). Reliance solely on either radiological or cardiographic evidence of left ventricular hypertrophy to confirm the presence of accompanying aortic stenosis can be misleading. The only constant sign of obstruction of the aortic valve is the presence of an aortic systolic murmur with a significant aortic systolic gradient. Confirmation is obtained by passing the dilator through the outflow tract of the left ventricle and gauging the width of the aortic valve. Routine left heart catheterization as advocated by Honey (1961) may provide additional information. However, it is salutary to reflect that in ten of our patients the peak aortic systolic gradient was below 65 , and yet critical stenosis was present in all. If pre-operative left heart catheterization had been used as the sole criterion for judging the severity of the aortic lesion, operative intervention might well have been postponed with deleterious results.

\section{Summary AND CONCluSIONS}

The clinical and hæmodynamic features in 15 patients with combined mitral and aortic stenosis have been presented. All underwent surgical relief of their dual obstruction, and the findings at operation have been correlated with pre-operative data. The only constant sign was the presence of an aortic systolic murmur in association with established mitral stenosis. While left heart catheterization before operation may provide additional information, the results taken alone may be equivocal. In isolated aortic stenosis, the aortic systolic gradient is not usually considered significant unless it is 60 or above. However, in combination with mitral stenosis, critical stenosis of the aortic valve may present with a peak aortic systolic gradient of little more than $20 \mathrm{~mm}$. $\mathrm{Hg}$. Conversely, where the gradient exceeds $100 \mathrm{~mm}$., the mitral stenosis may only be of comparatively mild degree, as in two of our patients.

Four deaths occurred, a mortality of 27 per cent. The causes of these are analysed in full. The survivors have been followed for a period varying from several months to four years after operation. Five are extremely well and completely asymptomatic, while a further four have derived considerable improvement.

The technique employed has been that of transventricular approach which affords easy access to both valves. The mitral valve is split to $3.5 \mathrm{~cm}$., the aortic valve to $3.0 \mathrm{~cm}$.

\section{ADDENDUM}

A further case of combined aortic and mitral stenosis has been treated surgically. This patient was a woman aged 35 years, with a history of Grade II dyspnœa extending over the previous two years. There was neither radiological nor cardiographic evidence of left ventricular hypertrophy. At operation both her aortic and mitral valves were found to be severely stenosed and the former was split to $3 \mathrm{~cm}$. while the mitral valve was split to $3.5 \mathrm{~cm}$. The peak aortic systolic gradient before operation was $95 \mathrm{~mm}$. and dropped to 35 following surgical treatment. There was moderate hypertension present in both left atrium and pulmonary artery beforehand. She is still in hospital but is progressing favourably.

The authors wish to express their thanks and appreciation to Dr. A. A. F. Peel for his helpful comments and criticism of this paper. They are also grateful to the physicians who referred their patients to the Thoracic Surgical Unit. 


\section{REFERENCES}

Anderson, M. W. (1961). The clinical course of patients with calcific aortic stenosis. Proc. Mayo Clin., 36, 439.

Baker, C., and Somerville, J. (1959). Clinical features and surgical treatment of fifty patients with severe aortic stenosis. Guy's Hosp. Rep., 108, 101.

Ellis, F. H., Jr., and Anderson, M. W. (1961). Surgical treatment of aortic stenosis: results of closed technics and of direct operation using hypothermia. Proc. Mayo Clin., 36, 451.

Honey, M. (1961). Clinical and hæmodynamic observations on combined mitral and aortic stenosis. Brit. Heart J., 23, 545

Ross, J. K. (1959). Failed mitral valvotomy. Thorax, 14, 320. 